\title{
Incidence of Placenta Accreta and its Complications in Cases of Previous Cesearean Sections with Placenta Previa Anterior at Al Hussein University Hospital
}

\author{
Abd Al Fattah Mohamed El sayed Al Senitty, Ashraf Hamdy Mohamed, \\ Ibrahim Mohammed Mohammed Ahmed* \\ Obstetrics and Gynecology Department, Faculty of Medicine, Al-Azhar University \\ * Corresponding author: Ibrahim Mohammed Mohammed Ahmed, E-mail: himakamar67@gmail.com
}

\begin{abstract}
Objective: Incidence of placenta accreta and its complications in cases of previous cesarean sections with placenta previa anterior at Al Hussein University Hospital.

Materials and Methods: Ultrasound is the recommended first step in the diagnosis of placenta previa accreta. Color Doppler ultrasound has been suggested to aid in the diagnosis of placenta previa accreta. Magnetic Resonance Imaging also was used.

Results: Cesarean Hysterectomy performed in all cases of accretion, bladder injury in 19 (47.5\%) cases, bowel injury in $1(2.5 \%)$ case, all cases received intraoperative blood transfusion, postoperative blood transfusion in 38 (95\%) cases and ICU admission in $25(62.5 \%)$ cases.

Conclusion: The incidences of placenta accreta in cases of previous cesarean section with placenta previa anterior were $63 \%$. Incidence, risk factors and Feto-maternal outcome of management of Patients with placenta accreta at Al Hussein University Maternity Hospital are comparable with those presented in several literatures.
\end{abstract}

Keywords: Placenta Accreta, Cesearean Sections, Placenta Previa Anterior.

\section{INTRODUCTION}

Morbid Adherent Placenta (M.A.P) occurs when the chorionic villi invade the myometrium abnormally. It is divided into three grades based on histopathology: placenta accreta where the chorionic villi are in contact with the myometrium, placenta increta where the chorionic villi invade the myometrium, and placenta percreta where the chorionic villi penetrate the uterine serosa ${ }^{(\mathbf{1})}$.

The exact pathogenesis of placenta accreta is unknown. A proposed hypothesis includes a maldevelopment of decidua, excessive trophoblastic invasion, or a combination of both (2). Defective decidualization, abnormal maternal vascular remodeling, excessive trophoblastic invasion, or combinations are considered to be the consequences of previous instrumentation ${ }^{(3)}$.

Placenta accreta is considered a severe pregnancy complication that may be associated with massive and potentially lifethreatening intrapartum and postpartum hemorrhage ${ }^{(4)}$. Placenta accreta is diagnosed ideally in the antenatal period by either sonographic or magnetic resonance imaging techniques. Several studies have demonstrated the usefulness of ultrasonography in making this diagnosis, particularly at more than 20 weeks' gestation ${ }^{(5)}$. Unfortunately, some cases of placenta accreta are diagnosed at the time of delivery when the mother experiences continued vaginal bleeding, or heavy vaginal bleeding when an attempt is In Egypt, Placenta accreta became prevalent mainly due to increased number of cesarean sections and multiparity (National Institutes of Health Consensus Development Conference Statement).As regard Al Hussein University Hospital number of cases of placenta accreta increased in the last few years. Patients with placenta accreta discovered at antenatal care visits diagnosed by ultrasonography, color Doppler or MRI and admitted in the maternal department for observation and to prevent the expected complications (Al Hussein university Hospital document centre).

\section{AIM OF THE WORK}

This work aims at determining the incidence of placenta accreta and its complications in cases of previous cesarean sections with placenta previa anterior and outcome of management of these 
complications at $\mathrm{Al}$ Hussein university hospital.

\section{PATIENTS AND METHODS}

\section{Type and Duration of the study:}

The study was a prospective cohort study including all cases admitted to $\mathrm{Al}$ Hussein university Hospital departments diagnosed as placenta previa anterior plus one or more previous cesarian sections during the period from March 2017 to March 2018.The study was approved by the ethics committee and after proper counseling, all women solicited for enrollment and provided written informed consent.

\section{Inclusion criteria include:}

1- Diagnosis: patients must have placenta previa anterior (margenalis, incomplete centralis or complete centralis).

2- Gestational age: more than 30 weeks at start of the study.

3- Parity: patients must have at least one previous cesarean section.

\section{Exclusion criteria:}

1) Patients with unscared uterus, or scared uterus rather than cesarean section.

2) Patients with normally situated placenta.

3) Placenta previa posterior.

4) Coagulopathy.

\section{Diagnosis:}

- Ultrasound is the recommended first step in the diagnosis of placenta previa accreta (7)

- Color Doppler ultrasound has been suggested to aid in the diagnosis of placenta previa accreta because it highlights abnormal areas of hypervascularity with dilated blood vessels within the placental and uterine tissues ${ }^{(\mathbf{8}, \mathbf{9}, \text { and 10)} \text {. }}$

Magnetic Resonance Imaging: In some cases Magnetic resonance imaging is very important in diagnosis of cases of placenta previa with suspicion of accretion when diagnosis of accretion is not completely established by ultrasound and color doppler.

Preoperative Preparation: Preoperative procedures were designed to improve the outcome, decrease the risk of complications and make the surgical approach of placenta accreta as safe as possible, these preparations include:

$>$ Complete laboratory investigations: complete blood count, liver function test, renal function tests and coagulation profile.

$>$ If anemia is discovered,it must be corrected properly before delivery by blood transfusion if Hemoglobin level is below $9 \mathrm{gm} / \mathrm{dl}$ or the fetus is more than 36 weeks gestation.

$>$ Anemia may be corrected by parenteral iron if Hemoglobin level is above $9 \mathrm{gm} / \mathrm{dl}$ or the fetus is less than 36weeks gestation.

$>$ Proper counseling of the patient and her relatives about her case and possible complications as cesarean hysterectomy, bladder, intestinal injury up to death. Patients and her relatives must sign an informed consent form acknowledging that they are aware of risk and complications. The surgery will not proceed unless the consent form is signed.

$>$ Saving of cross matched blood of the same blood group at least two bags of blood and four units of fresh frozen plasma and must be available before surgery.

$>$ Intestinal preparation (Bowel preparation) of the patient should be intestinal injury and done by mechanical method e.g enama every 6 hours the day before surgery, laxatives may be used as magnesium citrate Bisacodyl or Oral Sodium phosphate tablets (OsmoPrep).

$>$ Saving of Intensive Care Unit (ICU) bed before the operation as some 
patients need ICU admission after delivery.

\section{Intraoperative Morbidity (Follow Up data):}

- Cesarean hysterectomy performed in all cases of placenta accreta except a single case, 39 case $(97.5 \%)$, and 2 cases $(8.3 \%)$ of normal placenta due to severe bleeding from placental ped and uterine atony.

- Bladder injury occured in 19 cases $(47.5 \%)$ all of them approved placenta accreta, all of them did C.S hystrectomy and performed bladder repair.

- Bowel injury in 1 case (2.5\%) all of them had placenta accreta and C.S hysterectomy done.

- All cases of placenta accreta received intraoperative blood transfusion.

- Uterine preserving procedures (Bakry balloon) done in one case after spontaneous separation of the placenta.

\section{The postoperative follow up data were:}

- ICU admission occurred in 25 cases $(62.5 \%)$ of cases with placenta accreta, and in 2 cases $(3.1 \%)$ of cases with normal placenta.

- 38 cases $(95 \%)$ of cases with placenta accreta received postoperative blood transfusion.

- Early Postnatal Morbidity: No cases complicated with DIC or death.

\section{- Statistical analysis:}

P-value: is the probability of rejecting the null hypothesis (Ho). If the P-value is less than the chosen significance level then the null hypothesis (Ho) is rejected. The choice of significance level at which the Ho is rejected is arbitrary. Traditionally the 5, $1.5 \& 0.1 \%$ $(p<0.05,0.01,0.001)$ regions are used.

P: The probability/significance value

- P value > 0.05 (NS) Not significant

- $\mathbf{P}$ value $<0.05 *$ Significant at 0.05 level

- $\mathbf{P}$ value $<0.01 * *$ Significant at 0.01 Level
- Sensitivity, Specificity and Predictive value of Ultrasound and Doppler: The sensitivity and specificity of color Doppler imaging for diagnosing placenta previa accreta, especially anterior placenta accreta, have been high, because abnormal uteroplacental invasion can be detected with a high level of confidence.The ultrasonography and Doppler was suggestive of morbid adherence in 38 cases $(95.2 \%)$ of cases approved with placenta accreta, with accuracy 96\%,sensiyivity $95.24 \%, \quad$ specificity $97.3 \%$, +ve predictive value $98.36 \%$, and ve predictive value $92.31 \%$.

\section{RESULTS}

According to $\mathrm{Al}$ Hussein University Hospital, the number of cases diagnosed as placenta previa anterior with accretion at the period from March 2017 to March 2018 was 64 cases. 40 cases $(63 \%)$ of them were found as placenta previa accreta and diagnosis was established at time of admission and the remaining 33 cases (36\%) no accretion was found. The whole cases had delivered at least one previous cesarean section and all diagnosed by ultrasound and color Doppler. Cesarean Hysterectomy performed in all cases of accretion, bladder injury in $19(47.5 \%)$ cases, bowel injury in $1(2.5 \%)$ case, and all cases received intraoperative blood transfusion, postoperative blood transfusion in $38(95 \%)$ cases and ICU admission in 25 $(62.5 \%)$ cases.

Table (1): Relation between the number of previous cesarean section and the definitive diagnosis of normal and abnormal placenta in all cases.

\begin{tabular}{|l|l|l|l|l|}
\hline \multirow{2}{*}{ No. of P.C.S } & \multicolumn{3}{|l|}{ Definitive diagnosis } \\
\cline { 3 - 5 } & Accreta & $\begin{array}{l}\text { Not } \\
\text { accreta }\end{array}$ & Total \\
\hline \multirow{2}{*}{$\mathbf{1}$ CS } & No. & 2 & 9 & 11 \\
\cline { 2 - 5 } & $\%$ & 5 & 36.5 & \\
\hline \multirow{2}{*}{$\mathbf{C S}$} & No. & 10 & 5 & 15 \\
\cline { 2 - 5 } & $\%$ & 26 & 21.21 & \\
\hline \multirow{2}{*}{$3 \mathbf{C S}$} & No. & 15 & 5 & 20 \\
\cline { 2 - 5 } & $\%$ & 39.5 & 21.21 & \\
\hline \multirow{2}{*}{$4 \mathbf{C S}$} & No. & 11 & 5 & 16 \\
\cline { 2 - 5 } & $\%$ & 27.5 & 21.21 & \\
\hline \multirow{2}{*}{5 CS } & No. & 2 & 0 & 2 \\
\cline { 2 - 5 } & $\%$ & 5 & 0.00 & \\
\hline \multirow{2}{*}{ Total } & No. & 40 & 24 & 64 \\
\cline { 2 - 5 } & \multicolumn{3}{|l}{} \\
\hline \multirow{2}{*}{ p-value } & $<0.0001$ & & & \\
\hline
\end{tabular}


This table shows that there was a high significant relation between number of previous cesarean section and the definitive diagnosis of normal and abnormal placenta in all studied cases (P-value $<0.0001)$.

Table (2): Intraoperative complications of patients diagnosed as placenta previa accreta:

\begin{tabular}{|l|l|l|}
\hline Type of Complication & Number & Percentage\% \\
\hline $\begin{array}{l}\text { Cesarian } \\
\text { Hystrectomy }\end{array}$ & 39 & $97.5 \%$ \\
\hline Bladder injury & 19 & $47.5 \%$ \\
\hline Bowel injury blood & 40 & $2.5 \%$ \\
\hline $\begin{array}{l}\text { Operative blood } \\
\text { transfusion }\end{array}$ & 38 & $95 \%$ \\
\hline $\begin{array}{l}\text { Postoperative } \\
\text { transfusion }\end{array}$ & 25 & $62.5 \%$ \\
\hline ICU admission & 0 & $0 \%$ \\
\hline Death & & \\
\hline
\end{tabular}

\section{Basic Demographic features of Patients:}

(Table 3): demonstrates demographic variations of patients diagnosed as placenta previa accreta:

\begin{tabular}{|l|l|}
\hline \multirow{2}{*}{ Age } & \multicolumn{1}{|c|}{ Variations } \\
\hline Parity & $\begin{array}{l}\text { Common in age over 35 years . } \\
\text { caesaren section. }\end{array}$ \\
\hline BMI & More than 18. \\
\hline $\begin{array}{l}\text { Gestetional one previous } \\
\text { age } \\
\text { diagnosis }\end{array}$ & $\begin{array}{l}\text { More than 30 weeks gestation (Mean } \\
\text { GA 35 weeks). }\end{array}$ \\
\hline $\begin{array}{l}\text { Number } \\
\text { fetuses }\end{array}$ & Singelton or multiple pregnancies. \\
\hline
\end{tabular}

Table (4): Neonatal outcome in patients diagnosed as placenta previa accreta.

\begin{tabular}{|c|l|c|}
\hline & NUMBER & PERCENTAGE\% \\
\hline $\begin{array}{l}\text { APGAR } \\
\text { SCORE LESS } \\
\text { THAN 7 AT 5- } \\
\text { MIN }\end{array}$ & 6 & $15 \%$ \\
\hline RDS & 14 & $35 \%$ \\
\hline NICU & 6 & $15 \%$ \\
\hline PRE & & $50 \%$ \\
\hline $\begin{array}{c}\text { NEONATAL } \\
\text { DEATH }\end{array}$ & 1 & $2.5 \%$ \\
\hline
\end{tabular}

This table reveals that there was no significant relation between the neonatal ICU admission and pathological definitive diagnosis of normal and abnormal placenta in all studied cases $(\mathrm{P}$-value $=0.346)$.

\section{DISCUSSION}

In our study, the incidence of placenta accreta in cases of previous cesarean section with placenta previa anterior was $63 \%$ The marked increase in the incidence has been attributed to the increasing prevalence of cesarean delivery in recent years and we select more than risk factors in the inclusion criteria of patients included in the study(previous cesarean, placenta previa anterior reaching the scar, and the cases collected from a referral center Al Hussein university maternity hospital).

This study agrees with ACOG, as in our study, color Doppler finding revealed placenta accreta in 40 patients, $97.5 \%$ of these patients underwent hysterectomy.

Other reports have showed that the use of color Doppler imaging can improve the accuracy of the diagnosis of placenta accreta since the depth of invasion of the placenta into the uterine myometrium or serosa can be more accurately determined, especially in cases where the placenta is located anteriorly ${ }^{(11)}$.

ACOG (2002) demonstrated that color Doppler ultrasound in diagnosis of placenta accreta had sensitivity $82.4 \%$, specificity 96.8\%, PPV and NPV were $87.5 \%$ and $95.3 \%$ respectively. 
- This study demonstrated that color Doppler ultrasound in diagnosis of placenta accreta had very high sensitivity 95.24\%,NPV 92.32\%, accuracy 96\%, specificity $97.30 \%$, and PPV $98.36 \%$.

Most authors calculate the sensitivity, specificity, PPV and NPV by a combined assessment of all criteria using gray-scale ultrasound or color Doppler (8, 9,and 10). The present findings agree with those of Warshak et al. who analyzed 99 placenta accreta cases, found that approximately $75 \%$ required blood transfusion with a mean of $5.4 \pm 2.1$ units of RBCs Thus, blood transfusion should be anticipated, and massive transfusion is not rare in these obstetric patients. In the current study 56 cases of accreta 35 of them (63.5\%) admitted in ICU and 21 cases $(36.5 \%)$ not admitted in ICU,while 33 cases of normal placenta 2 case $(4.5 \%)$ not admitted in ICU and 31 cases $(95.4 \%)$ admitted in ICU.

No cases in our study complicated with DIC (disseminated intravascular coagulopathy) may be due to the sample size.

Other causes of early morbidity (coagulopathy, admission to the intensive care units, bladder injury \& bowel injury) are also high in patients with placenta accreta, as reported in previous study ${ }^{(\mathbf{1 2})}$. A retrospective study of 76 women with placenta accreta, bladder injury happen in 22 cases $(49 \%) \&$ ICU admission in 21 cases (54\%).

In our study the bladder was injured and repaired in 19 of 40 cases (47.5\%) all of them with abnormal placenta, while no bladder injury in cases of normal placenta. Bowel injury happen in 1 case only $(2.5 \%)$ all have abnormal placenta, while no bowel injury in cases of normal placenta. In cases of placenta accreta the incidence of perinatal complications is also increased mainly due to preterm birth and small for gestational age fetuses ${ }^{(\mathbf{1 2})}$. In the present study, the mean gestational age at delivery was $35 \pm 2.819$ weeks' gestation, the mean APGER score in cases of abnormal placenta $7.05 \pm 0.974$ with no significant relation(p-value0. 105).

Admission in neonatal ICU 6 cases (15\%) of abnormal placenta admited in NICU, while 34 cases(85\%) not admited in NICU with no significant relation (p-value0.346).

Maternal mortality has been reported in up to $7 \%$ of cases ACOG (2010). 109 cases of placenta accreta maternal death in 8 cases (7\%), In the current study there were no maternal deaths. This may be due to the sample size that was insufficient to detect the actual maternal mortality in these obstetric patients, diagnosed preoperatively, adequate blood, very experience surgical team and availability of resources improve maternal and fetal outcome and decrease maternal and fetal mortality.

\section{Further Future Studies Recommendations include the following:}

The study to be optimal, the number of cases included during the period of the study should be increased to include patients with accidently discovered during operation through increase the number of case observer clinicians in the hospitals. Also the period of the study must be adequate for proper preparing and follow up of the cases included. A wide spectrum study need to be performed to better identify the incidence, risk factors, outcome of management according to different strategies, neonatal outcome and fertility expectations in relation to the type of conservative surgery. Other studies with large number of cases to evaluate the accuracy of each color Doppler finding parameters.

While randomized controlled trials and large observational cohort studies that can be used to define best practice are lacking strategies to enhance early diagnosis, enhance preparation, and coordinate peripartum managment can be undertaken. Women with placenta previa overlying a uterine scar should be evaluated for the potential diagnosis of placenta accreta. Women with placenta previa or low lying placenta overlying a uterine scar early in pregnancy should be reevaluated in the third trimester with attention to the potential presence of placenta accreta.

\section{Limitations of our study include:}

1. Limited number of cases of placenta previa accreta attending $\mathrm{Al}$ Hussein University 
Hospital at the period of the study from March 2017 to March 2018.

2. Patients with accidently discovered placenta accreta during delivery not included in our study as we depend on patient admitted from outpatient clinic during antenatal care period.

3. We cannot be certain that all cases has been pathologically confirmed however, we restricted the inclusion of clinically defined cases to those requiring active managment.

4. It is thus unlikely that significant numbers of false positive cases have been included. Another potential limitation is that we cannot be certain that we have ascertained all cases.

\section{CONCLUSION}

Incidence, risk factors and Fetomaternal outcome of management of Patients with placenta accreta at Al Hussein University Maternity Hospital are comparable with those in the previous literatures.

\section{REFERENCES}

1. Tan CH, Tay KH, Sheah K, Kwek K, Wong $K$ and Tan HK (2007): Perioperative endovascular internal iliac artery occlusion balloon placement in management of placenta accreta. AJR Am J Roentgenol., 189:1158-63.

2. Garmi G, Salim R, Chulski A (2011): Epidemiology, etiology, diagnosis and management of Placenta Accreta., An International Journal of Obstetrics and Gynaecology, 48:799-803.

\section{Tantbirojn P, Crum CP and Parast MM} (2008): Pathophysiology of placenta creta: the role of decidua and extravillous trophoblast. Placenta, 29(7):639-45.

4. Faranesh R, Shabtai R, Eliezer $S$ and Raed S (2007): "Suggested approach for management of placenta percreta invading the urinary bladder." Obstetrics and Gynecology, 110(2): 512-515.
5. Comstock CH. (2005): Antenatal diagnosis of placenta accreta: a review. Ultrasound Obstet., and Gynecology, 26:89-96.

6. Kayem G, Johanson J, Grange G and Schmitz (2006): Clinical aspects and management of morbidly adherent placenta. Eur Clinics Obstet., and Gynaecology, 2: 139146.

7. Doumouchtis $\mathbf{S}$ and Arulkumaran $\mathbf{S}$ (2010): The morbidly adherent placenta: an overview of management options. Acta Obstet., Gynecol., Scand., 89(9):1126-33.

8. Chou M, Ho E and Lee Y (2010): Prenatal diagnosis of placenta previa by transabdominal color Doppler ultrasound. Ultrasound Obstet., and Gynecology, 15 (1): 28-35.

9. Levine D, Hulka CA, Ludmir J, Li W and Edelman RR (2016): Placenta: evaluation with color Doppler US, power Doppler US, and MR imaging. Radiology, 205: 773-6.

10. Lerner JP, Deane $S$ and Timor-Tritsch IE (2013): Characterization of placenta using transvaginal sonography and color Doppler imaging. Ultrasound Obstet., and Gynecology, 5: 198-201.

11. Twickler DM, Lucas MJ, Balis AB, Santos-Ramos R,Martin L, Malone S and Rogers B (2000): Color flow mapping for myometrial invasion in women with a prior caesarean delivery. J Matern., Fetal Med., 9: 330-335.

12. Eller G, Porter TT, Soisson $P$, and Silver $R$ (2009): Optimal management strategies for placenta, An International Journal of Obstetrics and Gynaecology, 116(5): 648-654.

13. Warshak CR, Ramos GA, Eskander R, Benirschke K, Saenz CC, Kelly TF, Moore TR and Resnik R (2010): Effect of redelivery diagnosis in 99 consecutive cases of placenta accreta.

Obstet., and Gynecology, 115(1):65-9s. 